\title{
sciendo
}

Transport and Telecommunication, 2021, volume 22, no. 2, 129-140

Transport and Telecommunication Institute, Lomonosova 1, Riga, LV-1019, Latvia

DOI 10.2478/ttj-2021-0010

\section{CONSTRUCTING REFERENCE PLANS OF TWO-CRITERIA MULTIMODAL TRANSPORT PROBLEM}

\author{
Krzysztof Przystupa ${ }^{1,2} *$, Zhang Qin $^{3}$, Serhii Zabolotnii ${ }^{4}$, Volodymyr Pohrebennyk, \\ Sergii Mogilei ${ }^{6}$, Chen Zhongju ${ }^{3} *$, Leszek Gil \\ ${ }^{1}$ Lublin University of Technology \\ Nadbystrzycka 36, 20-618 Lublin, Poland \\ k.przystupa@pollub.pl \\ ORCID: 0000-0003-4361-2763 \\ ${ }^{2}$ Department of Telecommunications, Lviv Polytechnic National University \\ Bandery 12, 79013 Lviv, Ukraine - postdoctoral academic training 14.05.2019-14.06.2019 \\ ${ }^{3}$ Yangtze University, Jingzhou \\ China.zqclr1123@163.com,chenzj@yangtzeu.edu.cn \\ ${ }^{4}$ Department of Computer Engineering and Information Technologies, \\ Cherkasy State Business College, 18000, Ukraine, Cherkasy, Chornovola, 243, \\ zabolotniua@gmail.com \\ ${ }^{5}$ Department of Ecological Safety and Nature Protection Activity, Lviv Polytechnic National University, \\ 79013, Lviv, Ukraine, St. Bandery, 12 \\ vpohreb@gmail.com \\ ${ }^{6}$ Department of Economic Cybernetics, East European University of Economics and Management, \\ 18000, Ukraine, Cherkasy, Khreschatyk street, 153, №1 \\ sergiymogiley@gmail.com \\ ${ }^{7}$ Department of Mechanics and Machine Building, University of Economics and Innovations in Lublin, \\ Projektowa 4, 20-209 Lublin, Poland \\ leszek.gil@wsei.lublin.pl \\ *Correspondence: k.przystupa@pollub.pl,chenzj@yangtzeu.edu.cn
}

The object of this study is a multicriteria transport problem, being stated for availability of several means of cargo delivery, meaning a multimodal transport problem. The optimization criteria of the multimodal transport problem described above are two objective functions of minimizing total transportation costs and level of transport risks. Three types of transport were selected for research: automobile, rail and river (inland waterway). The results of the study lay the foundation for development of a new valid algorithm for solving multimodal transport problems like multi-criteria optimization ones. The main advantage of such an algorithm lies in its higher potential convergence rate compared to classical numerical optimization methods, which now are predominantly used to solve the problems of this type. This advantage may not be decisive, but it appears to be at least quite an important argument when choosing the method of realization for two-criteria multimodal transport problems earlier considered, especially, in case of a large dimension. Moreover, the algorithm described in the work can be applied to similar problems with any number of types of transport and optimization criteria.

Keywords: algorithm, multimodal transport problem, multicriteria optimization, reference plan, algorithm adaptation

\section{Introduction}

Nowadays modeling (Bender, 2012) and experimental studies (Wang et al., 2019) as well as simplify the structure of objects (Shu and Kochan, 2013) are often used to solve various problems in science (Bender, 2012), technology (Irfan et al., 2019), medicine (Pelc et al., 2019) and industry (Hreha et al., 2015; Wojciechowski et al., 2018). They make it possible, by simplifying the objects or identifying their essential properties to investigate the behavior of complex devices and systems, and based on these studies, build theories that will suggest the optimum way of operation or predict their behavior under real operating conditions. The theoretical and experimental studies of an object, situation of phenomenon focus on a model (Bender, 2012). The model is something that simulates important features of the object, situation of phenomenon under study. It is essential to test a model how well it works when it is applied to the problems it was designed to simulate (Tamannaei and Irandoost, 2019; Yeromenko and Kochan, 2013). Often a model is used to make predictions (Beshley et al., 2015; Selech and Andrzejczak, 2020). 
Often the term model implies mathematical models that simulate real objects or situations by using the mathematical formulae. Why models, in particular mathematical ones useful? (Bender, 2012; Michałowska et al., 2019; Lonkwic and Syta, 2016; Lonkwic and Szydło, 2016).

1. They must formulate ideas precisely in order not to let important details slip by (Vasylkiv et al., 2009).

2. They are concise which encourages studies of different conditions for drawing either general or specific conclusions (Glowacz et al., 2017; Vasylkiv et al. 2009).

3. They help to reveal conditions that can be critical to the model so such conditions can be either studied deeper, say experimentally, or avoided or a real object is adjusted in the way to withstand these dangerous conditions (Chen et al., 2019; Klymash et al., 2012; Petruk, et al., 2016).

Mathematics now is playing a big role in the development of the life (Kvaternyuk et al., 2017), science (Chen et al., 2019), medicine (Pelc et al., 2019), technology (Irfan et al., 2019; Hreha et al., 2015), telecommunications (Beshley et al., 2015), ecology (Chen et al., 2019; Karpinski et al., 2018; Kvaternyuk et al., 2017; Petruk et al., 2016; Klymash et al., 2012; Pohrebennyk and Petryk, 2017; Pohrebennyk et al., 2017) and these areas are starting to influence mathematics. Interraction between Mathematics and other areas of science have important mutual effects and help to develop each other. This kind of interaction is very important in developing proper mathematical methods (Yeromenko et al., 2013) and tools for the varioussciences (Chen et al., 2019; Islam et al., 2018; Glowacz et al., 2017; Klymash et al., 2012; Petruk et al., 2016).

\section{State of the art}

The globalization processes influence greatly setting most complex ever tasks of transport logistics. The humanity needs for the rapid and high-quality transportation, primarily freight, require appropriate technical and analytical support. Therefore, as the logistics companies strive to minimize the risks and costs of transporting, the two-criteria multimodal transport problem is substantivized as the object of the research mentioned.

Complicated multimodal transport problems statement, as well as their multicriteria, with additional empirical complications taken into account require developing new and better methods for realizing problems of this type. This, in its turn, determines the relevance of this study - especially if there is a rather large number of shipping and delivery points in the transport problem (Przystupa, 2015; Przystupa, 2018).

The importance of transport systems optimization has recently become relevant. So, in (Borndörfer et al., 1998) the authors clearly indicate the need to apply mathematical methods in order to increase the efficiency of logistics management on a local or global scale, and it is to be primary for the methods of optimization theory (Niewczas et al., 2019).

The main methods to be discussed can be divided into two groups. The first group includes methods for solving transport problems (both classical and multimodal) with one optimization criterion. These are clearly associated with the methods of constructing reference plans for such a problem. In turn, the presence in the problem statement of more than one optimization criterion requires the use of methods of the second group - the ones for multi-criteria optimization.

The first group methods are described, in particular, in (Prívarová, 2016), with the methods of the north-west corner, the minimal element and the method of Vogel. These are the methods of solving the classical transport problem, the statement of which implies the presence of only one objective function and one mean of cargo delivery.

There are many numerical optimization methods implemented using special software for solving problems with account several means of cargo delivery. The simplest mathematical package is MS Excel, its use for solving problems of this type was proposed in (Borucka and Niewczas, 2019; Drašković et al., 2016). Also, the research of these means is given proper attention in (Chandrakantha, 2008; Ezeokwelume, 2016; Vats and KumarSingh, 2016). However, the small dimension of the problem set in this study is worth mentioning. Therefore, for solving higher-dimensional problems, much more powerful software tools may be required.

When the computer realization of transport problems of all types is considered, among many program products such mathematical packages as Mathcad and Matlab a can be used. Algorithms of their application in solving optimization problems are given in (Ovcharuk et al., 2015; Sengamalaselvi, 2017) respectively. However, more often MS Excel is used to solve the transport problems since it is simpler and more widespread (Andrzejczak et al., 2019). Therefore, MS Excel is used as a software in this paper.

Choosing specific means of cargo delivery, the internal features and regularities of the functioning of each of them are taken into account. As shown in (Huisman et al., 2005), for the example of NS Reizigers, 
the largest railway operator in the Netherlands, as well as fo $r$ other big transportation companies, such features often require separate studies. However, in this article, such level of the problem specification is considered excessive.

As for the methods of the second group, their rather successful review can be found in (Odu and Charles-Owaba, 2013). Among them one could distinguish the weighted sum method, the weighted minmax method, the reference point method etc. The common feature of these lies in finding the solution of a problem on the so-called Pareto set - therefore, the solution (set of solutions) of the multicriteria optimization problem should be called a solution optimal for Pareto (Przystupa, 2019).

A more detailed description of the methods of multicriteria optimization and decision-making with full disclosure of their principles and algorithms - is proposed by authors in (Ehrgott, 2005; Emmerich and Deutz, 2006). On the other hand, the application of these methods in specific fields of science and technology requires more in-depth study (Przystupa, 2013; Przystupa and Koziel, 2018). In particular, the application of methods of multicriteria optimization in the study of operation of multiprocessor embedded systems is presented in (Trystram, 2011), the authors describe the classes of newly developed approaches - algorithms of approximation and stochastic local search. There is also a narrower specialization of the application of multicriteria optimization methods - for example, in the field of radiation therapy (Bokrantz, 2013; Zhang and Chen; 2018) etc.

\section{Methods and Materials}

As any optimization problem, the two-criteria multimodal transport problem primarily contains the objective functions (Bokrantz, 2013):

$$
\begin{aligned}
& S=\sum_{i, j=1}^{m, n} a_{i j} x_{i j}+\sum_{i, j=1}^{m, n} b_{i j} y_{i j}+\sum_{i, j=1}^{m, n} c_{i j} z_{i j} \rightarrow \min ; \\
& R=\sum_{i, j=1}^{m, n} f_{i j} x_{i j}+\sum_{i, j=1}^{m, n} g_{i j} y_{i j}+\sum_{i, j=1}^{m, n} h_{i j} z_{i j} \rightarrow \min ,
\end{aligned}
$$

where:

$i=\overline{1, n}, j=\overline{1, m}-n$ points of dispatch and $m$ delivery points;

$x_{i j}, y_{i j}, z_{i j}$ - quantity of goods being transported from the $i$-th point of dispatch to the $j$-th delivery point respectively by automobile, railway and river transportation (required values);

$a_{i j}, b_{i j}, c_{i j}$ - cost of transportation of a unit of goods from the $i$-th point of dispatch to the $j$-th delivery point respectively by automobile, railway and river transportation;

$f_{i j}, g_{i j}, h_{i j}$ - risk of an accident to happen while transporting the goods from the $i$-th point of dispatch to the $j$-th delivery point respectively by automobile, railway and river transportation;

$S, R-$ the cost and risk functions respectively.

As for the admissible set of this problem, one of the possible restrictions in it may be the maximum total load carrying capacity of each kind of transport (Zabolotnii and Mogilei, 2019), however, this study is not subjected to this constrain. The only condition to be noted is that problem (1)-(2) is considered to be closed - that is, the quantities of supplies at dispatch points and the needs at delivery points are equal. This assumption is quite acceptable, for the open transport problem can be reduced to the closed one.

As for the risk parameters of transportation using different types of transport, their calculation depends on a number of factors and requires to be regarded in detail. That's why the formation of the risk objective function is carried out on a modal example.

On the other hand, the cost parameters of transportation are quite well-known values. Meanwhile, prices, for example, for road haulage may vary almost daily, and depend heavily on the transportation direction. Therefore, the points of dispatch and delivery are going to be taken into account in statement of the problem. To this effect, consider a map of elevators and transshipment terminals of «Nibulon» LLC (Figure 1). Among them the dispatch and delivery points are chosen arbitrarily.

Consider 3 dispatch points and 3 delivery points. Such dispatch points are identified so, as they have direct road, rail and river connections. In case of lack of direct connection, an alternative way of delivery through transit points is necessary.

The network of automobile ways and railways in Ukraine is fairly ramified, while inland waterway connections are the most reliable on large rivers such as the Dnipro and the Southern Bug. That is taken into consideration, and Table 1 of supplies and needs of transport problem (1)-(2) can be filled. 


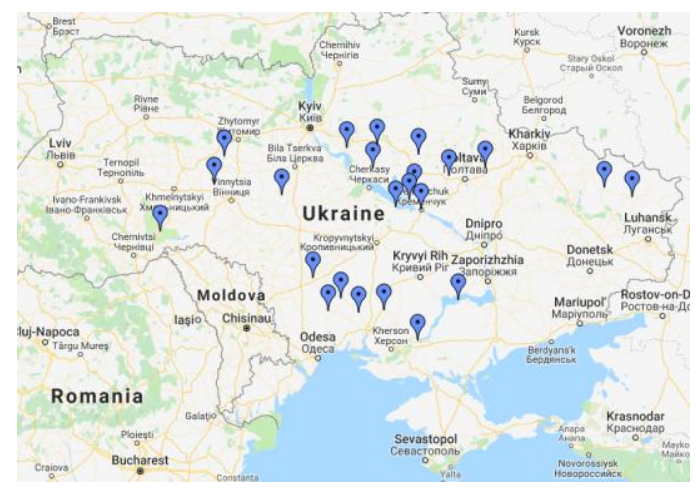

Figure 1. Elevators and transshipment terminals of «Nibulon» LLC (Nibulon LLC, 2019)

Table 1. The quantities of stocks at dispatch points and delivery points needs of «Nibulon» LLC

\begin{tabular}{|l|l|l|}
\hline № & Dispatch point & Quantities of stocks (tons) \\
\hline 1 & Pereyaslav-Khmelnitsky (Kyiv region) & 480 \\
\hline 2 & Kremenchuk (Poltava region) & 420 \\
\hline 3 & Voznesensk (Mykolaiv region) & 300 \\
\hline Total & All dispatch points: & 1200 \\
\hline № & Delivery point & Quantities of needs (tons) \\
\hline 1 & Mykolaiv & 320 \\
\hline 2 & Kherson & 500 \\
\hline 3 & Odesa (seaport) & 380 \\
\hline Total & All delivery points: & 1200 \\
\hline
\end{tabular}

As delivery points, the cities of Kherson, Mykolaiv and Odesa were chosen as one of the largest port cities in Ukraine.

Next, it is necessary to determine the distances between the specified points of dispatch and delivery of goods: by road, by rail and by rivers.

Distance by automobile roads can be calculated using special services, which are located on the sites of carriers. Using this service on the site (Della TM, 2019), Table 2 of distances (in kilometers) between points of dispatch and delivery points is filled. Note that transit points (requisite of the service «Via») are not indicated.

Table 2. Distances (km) between points of dispatch and delivery (automobile roads)

\begin{tabular}{|l|l|l|l|}
\hline Points of dispatch and delivery & Pereyaslav-Khmelnitsky & Kremenchuk & Voznesensk \\
\hline Mykolaiv & 417 & 318 & 90 \\
\hline Kherson & 478 & 379 & 156 \\
\hline Odesa (seaport) & 555 & 473 & 143 \\
\hline
\end{tabular}

In fact, service (Della TM, 2019) uses service (Google Maps, 2019) in its work, to construct rail and river routes and to determine distances between settlements, so we use the second service directly. The obtained data is presented in Tables 3 and 4.

Table 3. Distances $(\mathrm{km})$ between points of dispatch and delivery (railways)

\begin{tabular}{|l|l|l|l|}
\hline Points of dispatch and delivery & Pereyaslav-Khmelnitsky & Kremenchuk & Voznesensk \\
\hline Mykolaiv & 605 & 320 & 106 \\
\hline Kherson & 674 & 388 & 208 \\
\hline Odesa (seaport) & 652 & 472 & 154 \\
\hline
\end{tabular}

Table 4. Distances $(\mathrm{km})$ between points of dispatch and delivery (river connection)

\begin{tabular}{|l|l|l|l|}
\hline Points of dispatch and delivery & Pereyaslav-Khmelnitsky & Kremenchuk & Voznesensk \\
\hline Mykolaiv & 979 & 650 & 100 \\
\hline Kherson & 872 & 587 & 200 \\
\hline Odesa (seaport) & 1064 & 780 & 232 \\
\hline
\end{tabular}

In Table 5 rates for inland transportation by road, rail and river transport are given. According to data (Zhang et al., 2018), the value of tariff for road transportation in 2018, indicated in Table 5, fluctuated within 22,5-27,5 UAH. Table 5 contains the average value of this data. 
Data on rail and river traffic from Table 5 is shown in (Kirichevsky, 2019) for KremenchukMykolaiv route as of mid-October 2019, or for the planned increase of prices in railway transportation by $25 \%$.

Table 5. Tariffs for cargo transportation within Ukraine

\begin{tabular}{|l|l|l|}
\hline Type of transport & Method of calculating the fare & Tariff \\
\hline Automobile & Tilt transportation with load-carrying capacity 20 ton & $25 \mathrm{UAH} / \mathrm{km}(1 \mathrm{USD} / \mathrm{km})$ \\
\hline Railway & For 1 ton & $230 \mathrm{UAH}(9.2 \mathrm{USD})$ \\
\hline River & For 1 ton & $250 \mathrm{UAH}(10 \mathrm{USD})$ \\
\hline
\end{tabular}

The distances between Kremenchuk and Mykolaiv are known from Tables 2- 4. Consequently, it is possible to calculate the reduced (in UAH/ton-kilometer) tariffs for all types of transportation (Table 6).

Finally, Tables 7- 9 contain data on the cost of transportation of 1 ton of cargo between the points of dispatch and delivery for each type of transport.

Table 6. Reduced tariffs for cargo transportation within Ukraine

\begin{tabular}{|l|l|}
\hline Type of transport & Tariff, UAH / ton-kilometer \\
\hline Automobile & $25 / 20=1.25$ \\
\hline Railway & $230 / 320=0.72$ \\
\hline River & $250 / 650=0.38$ \\
\hline
\end{tabular}

Table 7. The cost of transportation of 1 ton of cargo between dispatch and delivery points (roads)

\begin{tabular}{|l|l|l|l|}
\hline Points of dispatch and delivery & Pereyaslav-Khmelnitsky & Kremenchuk & Voznesensk \\
\hline Mykolaiv & 521.25 & 397.5 & 112.50 \\
\hline Kherson & 597.50 & 473.75 & 19.005 \\
\hline Odesa (seaport) & 693.75 & 591.25 & 178.75 \\
\hline
\end{tabular}

Table 8. The cost of transportation of 1 ton of cargo between dispatch and delivery points (railway)

\begin{tabular}{|l|l|l|l|}
\hline Points of dispatch and delivery & Pereyaslav-Khmelnitsky & Kremenchuk & Voznesensk \\
\hline Mykolaiv & 435.60 & 230.00 & 76.32 \\
\hline Kherson & 485.28 & 279.36 & 149.76 \\
\hline Odesa (seaport) & 469.44 & 339.84 & 110.88 \\
\hline
\end{tabular}

Table 9. The cost of transportation of 1 ton of cargo between dispatch and delivery points (river)

\begin{tabular}{|l|l|l|l|}
\hline Points of dispatch and delivery & Pereyaslav-Khmelnitsky & Kremenchuk & Voznesensk \\
\hline Mykolaiv & 372.02 & 250.00 & 38.00 \\
\hline Kherson & 331.36 & 223.06 & 76.00 \\
\hline Odesa (seaport) & 404.32 & 296.40 & 88.16 \\
\hline
\end{tabular}

Tables 10-12 contain model data on the risk-level of transportation (measured as a percentage or share) of 1 ton of cargo between dispatch and delivery points for each type of transport.

Table 10. The risk of transportation of 1 ton of cargo between dispatch and delivery points (roads)

\begin{tabular}{|l|l|l|l|}
\hline Points of dispatch and delivery & Pereyaslav-Khmelnitsky & Kremenchuk & Voznesensk \\
\hline Mykolaiv & 0.02 & 0.08 & 0.02 \\
\hline Kherson & 0.07 & 0.05 & 0.07 \\
\hline Odesa (seaport) & 0.07 & 0.08 & 0.09 \\
\hline
\end{tabular}

Table 11. The risk of transportation of 1 ton of cargo between dispatch and delivery points (railway)

\begin{tabular}{|l|l|l|l|}
\hline Points of dispatch and delivery & Pereyaslav-Khmelnitsky & Kremenchuk & Voznesensk \\
\hline Mykolaiv & 0.03 & 0.07 & 0.03 \\
\hline Kherson & 0.09 & 0.04 & 0.05 \\
\hline Odesa (seaport) & 0.06 & 0.07 & 0.08 \\
\hline
\end{tabular}

Table 12. The risk of transportation of 1 ton of cargo between dispatch and delivery points (river)

\begin{tabular}{|l|l|l|l|}
\hline Points of dispatch and delivery & Pereyaslav-Khmelnitsky & Kremenchuk & Voznesensk \\
\hline Mykolaiv & 0.01 & 0.06 & 0.02 \\
\hline Kherson & 0.05 & 0.03 & 0.06 \\
\hline Odesa (seaport) & 0.05 & 0.04 & 0.08 \\
\hline
\end{tabular}




\section{Results and Discussion}

\subsection{Problem implementation algorithm}

To realize the problem (1)-(2), an appropriate algorithm for constructing its reference plans (Johnson et al., 2016), among which the optimal one is to be determined, is described and applied. The optimization criterion (1) - the objective function of cost is to be started with (Kirichevsky, 2019).

The following notation is introduced:

$A=\left(a_{i j}\right), B=\left(b_{i j}\right), C=\left(c_{i j}\right)$

the cost matrices of transportation by road, rail and water transport, respectively;

$X=\left(x_{i j}\right), Y=\left(y_{i j}\right), Z=\left(z_{i j}\right)$

matrices of road, rail and water transport plans, respectively.

The matrix of the compromise transportation plan as $T=\left(t_{i j}\right)-$ with lower indexes: $S$ for cost function $\left(T_{S}\right)$ and $R$ for risk function $\left(T_{R}\right)$, is to be denoted.

The relationship of the product of cost matrixes and transportation plans (for example, road transport) is as follows:

$A \times X=\left(\mathrm{a}_{i j}\right) \times\left(x_{i j}\right)=\sum_{i, j=1}^{m, n} a_{i j} x_{i j}$.

Thus, taking into account (3), the objective function (1) is as follows:

$S=A \times X+B \times Y+C \times Z \rightarrow \min$.

1. Build the Steiner matrix $S t_{S}$, that is, the matrix which elements are the minimum (by the optimization criterion) cost of transportation of each type of transport from the $i$-th point of dispatch to the $j$-th delivery point:

$S t_{S}=\left(s t_{i j}\right)=\left(\min \left(a_{i j} ; b_{i j} ; c_{i j}\right)\right)$.

$S t_{S}=\left(\begin{array}{ccc}372.02 & 230 & 38 \\ 331.36 & 223.6 & 76 \\ 404.32 & 296.4 & 88.16\end{array}\right)$.

That is, the minimum value of the cost of transport $S_{\min }$ is calculated as follows:

$S_{\min }=S t_{S} \times T_{S}$

2. Write the objective cost minimization function - the sum of the products of St matrix elements and the values of the corresponding indicators of the reference trade-off plan of transportation:

$S=S t_{S} \times T_{S}^{*} \rightarrow \min$,

where: $T_{S}^{*}$ - the matrix of the reference (non-optimal) compromise transportation plan.

3. Minimize the objective function $S$ - obtain the minimum value of the cost of transportation (6) and the optimal compromise transport plan - that is, the condition $T_{S}{ }^{*}=T_{S}$ is satisfied. In this case, the minimum value of function $S=249,829.2 \mathrm{UAH}$, and matrix

$T_{S}=\left(\begin{array}{ccc}0 & 400 & 80 \\ 320 & 100 & 0 \\ 0 & 0 & 300\end{array}\right)$.

4. Generate a multitude of combinations of reference plans for each type of transport, among which we select the optimal one. The main condition for the existence of each combination of such a set: the sum of the corresponding elements of its reference plans should be equal to the corresponding element of the matrix $T$. 
Therefore, the general algorithm for determining the compromise reference plan of the onecriterial multimodal transport problem can be arranged in a block scheme that follows (Figure 2):

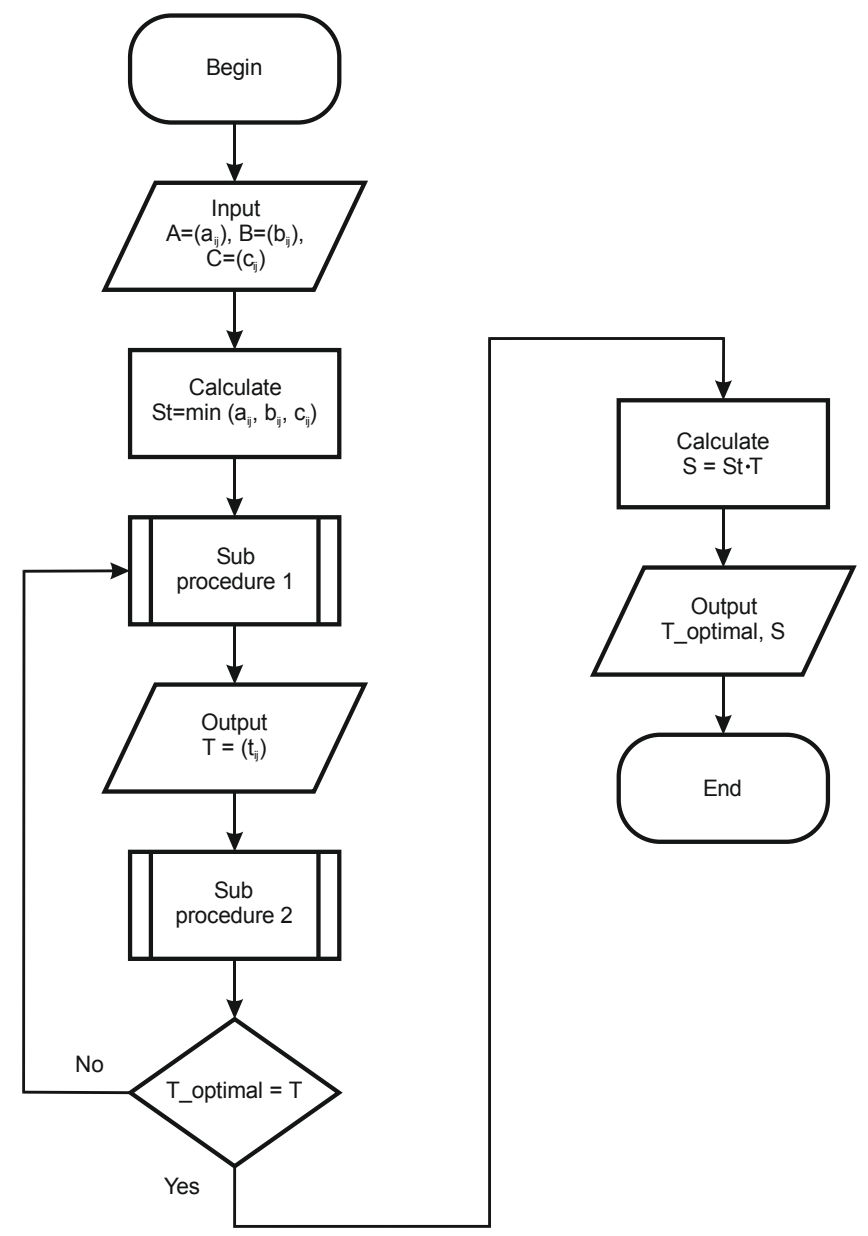

Figure 2. The algorithm for determining compromise reference plan of the one-criterial multimodal transport problem

The algorithm shown (Figure 2) should be explained. After matrices of transportation costs for each kind of transport and Steiner matrix calculation are introduced, the subprogram "Sub procedure 1" is carried out. The proposed subprogram is launched to search for the reference - initial or optimized - plan of a transport problem according to any of the proposed methods (the methods of the north-west corner, the minimal element and the method of Vogel) (Prívarová, 2016). Besides, on this stage of the problem realization constrains on the quantities of supplies at dispatch points and the needs at delivery points should be taken into account (Andrzejczak and Selech, 2017).

After the reference plan of the problem is determined, it should be checked for being optimal (for instance, by the method of potentials) (Prívarová, 2016). That is what is happening on the realization stage of the "Sub procedure 2" program, that results in calculating the optimal value of the objective function, and the result of the program realization is displayed on a monitor - that is a compromise reference plan of the given one-criterial problem.

It worth mentioning that subprograms Sub procedure 1 and Sub procedure 2 don't need a more detailed description within the given analysis. Virtually any software (MS Excel, Mathcad, Matlab etc.) contains standard calculating tools for realizing the algorithms, described in the given procedures (Andrzejczak et al., 2017).

It is important to note, that the algorithm, described in Figure 2 is almost identical to that of the standard transport problem. The only significant peculiarity of this algorithm is calculation of the Steiner matrix, based on the modality of the problem set in the research.

To realize the multicriteria multimodal transport problem, the proposed algorithm is to be applied to the objective function of minimizing transportation risk.

Then, similarly, paragraphs 1-4 are to be implemented for the function of risk, so that one obtains the appropriate Steiner matrix $S t_{R}$ and a compromise transport plan matrix $T_{R}$ : 


$$
\begin{aligned}
S t_{R} & =\left(\begin{array}{lll}
0.01 & 0.06 & 0.02 \\
0.05 & 0.03 & 0.05 \\
0.05 & 0.04 & 0.08
\end{array}\right), \\
T_{R} & =\left(\begin{array}{ccc}
320 & 0 & 160 \\
0 & 200 & 220 \\
0 & 300 & 0
\end{array}\right) .
\end{aligned}
$$

Next, compare matrices $T_{S}$ and $T_{R}$. The following cases are possible:

1. $T_{S}=T_{R}$. In this case, the optimal combinations of reference plans, according to the criteria of minimizing the cost and risk functions coincide. This very optimal combination is the solution of the problem (1)-(2).

2. $T_{S} \neq T_{R}$. In this case, there are no identical cost and risk optimal combinations of reference plans (as in the example above). Thus, it is necessary to find some intermediate (between minimum cost and risk) combination of reference plans (optimal for Pareto) - and the algorithm of its determining should be the subject of further research.

\subsection{Multicriteria problem and its solution}

To demonstrate search for intermediate solution, suppose that there exists at least one solution for problem (1)-(2), that is, there exists at least one combination $\left(T^{a} ; T^{r} ; T^{w}\right)$ of the reference plans in the problem given for each means of transport (automobile, railway, water respectively) taken separately, whereas the condition (8) is implemented:

$T^{a}+T^{r}+T^{w}=T$.

Back to the abovementioned method of weighted sums (Zabolotnii and Mogilei, 2019), notice that its principle lies in constructing a resultant of several objective functions of the problem into the optimization function. The latter is actually a superposition of all objective functions of the optimization problem to be solved.

In the problem (1)-(2) such superimposition $\mathrm{F}$ is represented as:

$T=w_{s} \cdot S+w_{R} \cdot R \rightarrow \min$,

where:

$0 \leq w_{s}, w_{R} \leq 1$ are weight coefficients for cost and risk respectively, whereas $w_{s}+w_{R}=1$.

It is worth noting, the correctness of such a resultant in the context of problem (1)-(2) is quite doubtful as transport cost and risk in the transportation are differently measured. Further, the value of objective functions should be given in the same units of measurement.

In case, $w_{s}=w_{R}=0.5$, objective functions of the problem are regarded of equal weight.

Similarly, suppose matrix $T$ is superimposition of matrices $T_{S}$ and $T_{R}$ :

$T=K_{S} \times T_{S}+K_{R} \times T_{R}$,

where:

$K_{S}=\left(k_{i j}^{S}\right), K_{R}=\left(k_{i j}^{R}\right), 0 \leq k_{i j}^{S}, k_{i j}^{R} \leq 1$, the elements of matrices of weight coefficients of reference plans for cost and risk respectively, whereas $k_{i j}^{S}+k_{i j}^{R}=1$ (the sums of the matrix elements are 1).

The matrix dimension $K_{S}, K_{R}$ coincide with that of the problem and for this particular case it is $3 \times 3$.

Practically, before defining, under statement (8), combination $\left(T^{a} ; T^{r} ; T^{w}\right)$ for the reference plans of the problem matrix $T$ is to be calculated. It may be done for statement (10) though, however, the issue of the choice in the objective function is not completely solved. Furthermore, the problem remains unrealized for the absence of the clear optimization criterion.

For this reason, congruence (10) will be taken into account separately for objective functions of minimization of cost and risk. Such cases for statement (9) are regarded as periphery and integral. Therefore, first integral case completely denies objective function of risk. In other words, weight 
coefficient for objective function of cost in this case is 1 , and function of cost is 0 . The second integral case is quite opposite: objective function of risk has the weight of 1 , and function of cost has 0 .

Obviously, the first integral case is $w_{S}=k_{i j}^{S}=1 ; w_{R}=k_{i j}^{R}=0$, and the second is $w_{S}=k_{i j}^{S}=0$; $w_{R}=k_{i j}^{R}=1$. The result is clear, for, in presence of the only objective function of optimization the values of relevant reference plans are known.

Further consider a model problem in which it is supposed that objective functions of cost and risk are given in similar measurements. Therefore, let Steiner matrix remain constant, and the same matrix, for the criterion of risk, is as follows:

$S t_{R}=\left(\begin{array}{ccc}300 & 230 & 40 \\ 340 & 230 & 80 \\ 410 & 300 & 100\end{array}\right)$.

Also assume that the objective functions (1) and (2) are regarded of equal weight.

Software implementation of the model problem presents non-peripheral variant of the problem. So, matrices of the weight coefficients for the reference plans will be as follows:

$K_{S}=\left(\begin{array}{ccc}0.6875 & 0.75 & 1 \\ 0.6875 & 0 & 1 \\ 0 & 1 & 1\end{array}\right), K_{R}=\left(\begin{array}{ccc}0.3125 & 0.25 & 0 \\ 0.3125 & 1 & 0 \\ 1 & 0 & 0\end{array}\right)$.

According to (10), optimal reference plan in this case will be:

$T=\left(\begin{array}{ccc}100 & 300 & 80 \\ 220 & 200 & 0 \\ 0 & 0 & 300\end{array}\right)$.

The obtained result enables passing to statement (8) that is obviously insufficient for obtaining the single solution of problem (1)-(2). Meanwhile, the proposed method of weighted sums is one of the few methods of multi-criteria optimization that may be applied to solve the problem of the research given. Probably, the application of other methods could affect the whole algorithm of the problem solution but this issue needs to be given a special study.

Obviously, among alternative methods of the problem solution, beside the weighted sum method, there is the weighted min-max method, as well as the reference point method and others, described in (Ehrgott, 2005; Emmerich and Deutz, 2006; Odu, et al., 2013). Thus, with account of its meaning, the weighted min-max method could considerably influence the algorithm of searching for reference plans of multicriteria multimodal transport problem. The same is to be said about the reference point method.

As for applying a weighted min-max method for realization of the multimodal transport problem with the classic criterion of minimizing the cost function, it is worth here dividing cargo transportation costs into permanent and variable. Permanent costs should be regarded as those that are inevitable in any case (they are exterior factors for the business model under analysis) (Selech et al., 2018). In contrast, variable costs could be minimized. From this point of view, most important element in minimizing the value of the transportation cost is the type of transport (and, thus, the constituent of the objective function), variable costs of which are most important as is to be minimized. However, both interrelated permanent and variable costs in a certain type of transport, and interrelated absolute values for permanent and variable costs for different types of transport must be taken into account. Indeed, it's impossible to give preference to the means of cargo delivery that, among others, possesses the largest value of permanent costs (Tawfik, Limbourg, 2018).

In conclusion, statements (8) and (10) appear insufficient for the proper solution of the problem. To achieve its objective functions of optimization, additional propositions, like (9), should be introduced, with avoiding periphery cases in general problem setting.

\section{Conclusion}

The article considers adaptation of a new algorithm for constructing reference plans of a multimodal transport problem to be proposed on the basis of real data of the Ukrainian company «Nibulon» LLC (Nibulon LLC, 2019), as well as model indicators. The basis of such an algorithm is the so-called Steiner 
method of constructing reference plans. In course of research, the proposed method had been expanded and specified. That revealed a number of peculiar details, equally important for problem statement and for the technique of its realization. So, this is the scientific novelty of this research. Also, the research contains a block scheme for Steiner algorithm, for the case of one-criterial multimodal transport problem that allows its program realization, first of all, using the standard mathematical software.

Foremost, it is worth considering a predictably large number of already known approaches that may be properly applied to solve the problem set in the research (the weighted sum method, the weighted min-max method, the reference point method etc). Therefore, it is possible to ascertain the search for optimal solution of the problem given.

On the other hand, the obtained research results enable further study of peculiarities of the multicriteria optimization methods to multimodal transport problems. In particular, the study regards a large dimensional problem with two objective functions. The development of new methods precisely for a two-criteria multimodal transport problem is believed to be sufficient to propagate these approaches to similar problems with more optimization criteria.

As for the latter, their realization algorithms can be applied to business models of many other companies but «Nibulon» LLC. Among others, the biggest company in Ukraine, «Nova Poshta» LLC (Nova Poshta LLC, 2020), specializing in load delivery can be distinguished. Due to its cooperation with European «DPD group» LLC (DPD group LLC, 2020) «Nova Poshta» has arranged its work not only in Ukraine but also in the EU. As for «DPD group», it is working all over the world. Therefore, effective algorithms for realization of multicriteria multimodal transport problems potentially are interesting for many Ukrainian, European and world companies.

Funding: This work was financed in the framework of the project Lublin University of Technology Regional Excellence Initiative, funded by the Polish Ministry of Science and Higher Education, contract no. 030/RID/2018/19.

\section{References}

1. Andrzejczak, K., Młyńczak, M., Selech, J. (2017) Assessment model of operational effectiveness related to newly operated public means of transport. In: Safety and Reliability - Theory and Applications, ed. Marko Cepin, Radim Briš - London, United Kingdom: CRC Press Taylor \& Francis Group, pp. 3455-3460, 27th European Safety and Reliability Conference ESREL 2017.

2. Andrzejczak, K., Młyńczak, M., Selech, J. (2019) Computerization of Operation Process in Municipal Transport. In: Zamojski W., Mazurkiewicz J., Sugier J., Walkowiak T., Kacprzyk J. (eds) Contemporary Complex Systems and Their Dependability. DepCoS-RELCOMEX 2018. Advances in Intelligent Systems and Computing, 761. Springer.

3. Andrzejczak, K., Selech, J. (2017) Quantile analysis of the operating costs of the public transport fleet. Transport Problems. 12(3), 103-111, DOI: 10.20858/tp2017.12.3.10.

4. Bender, E. A. (2012) An introduction to mathematical modeling. Courier Corporation.

5. Beshley, M., Romanchuk, V., Seliuchenko, M., Masiuk, A. (2015, February) Investigation the modified priority queuing method based on virtualized network test bed. In: The Experience of Designing and Application of CAD Systems in Microelectronics, IEEE, 1-4.

6. Bokrantz, R. (2013) Multicriteria optimization for managing tradeoffs in radiation therapy treatment planning (Doctoral dissertation, KTH Royal Institute of Technology).

7. Borndörfer, R., Grötschel, M., Löbel, A. (1998) Optimization of transportation systems.

8. Borucka, A., Niewczas, A. (2019) Forecasting the readiness of special vehicles using the semiMarkov model. Eksploatacja i Niezawodność - Maintenance and Reliability, 21(4), 662.

9. Chandrakantha, L. (2008) Using Excel Solver in optimization problems. Mathematics and Computer Science Department.

10. Chen, D., Zhang, Y., Gao, L., Thompson, R. G. (2019) Optimizing Multimodal Transportation Routes Considering Container Use. Sustainability, 11, 19, 5320.

11. Della TM. URL: https://della.com.ua (accessed on 15 November 2019).

12. DPD group, LLC. URL: https://www.dpd.com/group/en/ (accessed on 20.06.2020).

13. Drašković, M., Malyaretz, L., Dorokhov, O. (2016) Solution of the problem of critical path's finding in Excel on the basis of reducing it to ordinary transportation task (Doctoral dissertation, Univerza $\mathrm{v}$ Mariboru, Fakulteta za logistiko).

14. Ehrgott, M. (2005). Multicriteria optimization (491). Springer Science Business Media.

15. Emmerich, M., Deutz, A. (2006) Multicriteria optimization and decision making. LIACS. Leiden university, NL. 
16. Ezeokwelume, O. (2016) Solving Linear Programming Problems and Transportation Problems using Excel Solver. International Journal of Scientific Engineering Research, 7 (9), 134-142.

17. Glowacz, A., Glowacz, W., Glowacz, Z., Kozik, J., Gutten, M., Korenciak, D., ... Carletti, E. (2017) Fault diagnosis of three phase induction motor using current signal, MSAF-Ratio15 and Selected Classifiers. Archives of Metallurgy and Materials, 62(4), 2413-2419.

18. Google Maps. URL: https://www.google.com.ua/maps (accessed on 15 November 2019).

19. Hreha, P., Radvanská, A., Hloch, S., Peržel, V., Królczyk, G., Monková, K. (2015) Determination of vibration frequency depending on abrasive mass flow rate during abrasive water jet cutting. The International Journal of Advanced Manufacturing Technology, 77(1-4), 763-774.

20. Huisman, D., Kroon, L. G., Lentink, R. M., Vromans, M. J. (2005) Operations research in passenger railway transportation. Statistica Neerlandica, 59(4), 467-497.

21. Irfan, M., Saad, N., Alwadie, A., Awais, M., Sheikh, M. A., Glowacz, A., Kumar, V. (2019) An Automated Feature Extraction Algorithm for Diagnosis of Gear Faults. Journal of Failure Analysis and Prevention, 19(1), 98-105.

22. Islam, T., Vu, H. L., Panda, M., Ngoduy, D. (2018) A study of realistic dynamic traffic assignment with signal control, time-scale, and emission. Journal of Intelligent Transportation Systems, 22(5), 446-461.

23. Johnson, P., Nguyen, D., Ng, M. (2016) Large-scale network partitioning for decentralized traffic management and other transportation applications. Journal of Intelligent Transportation Systems, 20(5), 461-473.

24. Karpinski, M., Pohrebennyk, V., Bernatska, N., Ganczarchyk, J., Shevchenko, O. (2018) Simulation of Artificial Neural Networks for Assessing the Ecological State of Surface Water, 18th International Multidisciplinary Scientific GeoConference SGEM 2018, Albena, Bulgaria, 693-700.

25. Kirichevsky, I. Mission (im)possible: can it be possible to increase river carriage of grain at least a million tons? URL: https://svidok.info/ru/news/9187 (accessed on 15 November 2019).

26. Klymash, M., Beshley, M., Koval, V. (2012, February) The model of prioritization of service for efficient usage of resource multiservice network. In Proc. of 11th International Conference Modern Problems of Radio Engineering, Telecommunications and Computer Science TCSET.

27. Kvaternyuk, S., Pohrebennyk, V., Petruk, R., Kochanek, A., Kvaternyuk, O. (2017) Multispectral television measurements of parameters of natural biological media. In: 17th International Multidisciplinary Scientific GeoConference SGEM, 17(51), 689-696.

28. Lonkwic, P., Syta, A. (2016) Nonlinear analysis of braking delay dynamics for the progressive gears in variable operating conditions. Journal of Vibroengineering, 18, 7.

29. Lonkwic, P., Szydło, K. (2016) Reduction of the cabin acoustic emission by the selection of an optimum stiffening method for the cabin panels. Journal of Measurements in Engineering, 4(2).

30. Michałowska, J., Mazurek, P. A., Gad, R., Chudy, A., Kozieł, J. (2019, June) Identification of the Electromagnetic Field Strength in Public Spaces and During Travel. In: 2019 Applications of Electromagnetics in Modern Engineering and Medicine (PTZE), IEEE, 121-124.

31. Nibulon LLC. URL: http://www.nibulon.com/data/branches/route-maps.html (accessed on 15.11.2019).

32. Niewczas, A., Rymarz, J., Dębicka, E. (2019) Stages of operating vehicles with respect to operational efficiency using city buses as an example. Eksploatacja $i$ Niezawodność - Maintenance and Reliability, 21.

33. Nova Poshta LLC. URL: https://novaposhta.ua/international_delivery/biznes_klientam_md (accessed on 20.06.2020).

34. Odu, G. O., Charles-Owaba, O. E. (2013) Review of multi-criteria optimization methods-theory and applications. IOSR Journal of Engineering (IOSRJEN), 3(10), 1-14.

35. Ovcharuk, V., Vovkodav, N., Kryvets, T., Ovcharuk, I. (2015) Linear programming in Mathcad on the example of solving the transportation problem. Наукові праці Начіонального університету харчових технологій, 21(4), 110-117.

36. Pelc, M., Khoma, Y., Khoma, V. (2019) ECG Signal as Robust and Reliable Biometric Marker: Datasets and Algorithms Comparison. Sensors, 19(10), 2350.

37. Petruk, R., Pohrebennyk, V., Kvaternyuk, S., Bondarchuk, O., Cygnar, M. (2016) Multispectral television monitoring of contamination of water objects by using macrophyte-based bioindication. International Multidisciplinary Scientific GeoConference: SGEM: Surveying Geology \& mining Ecology Management, 2, 597-601.

38. Pohrebennyk, V., Petryk, A. (2017) The degree of pollution with heavy metals of fallow soils in rural administrative units of Psary and Płoki in Poland. In: 17th International Multidisciplinary Scientific GeoConference, SGEM, Albena, Bulgaria, 17(52), 967-974. 
39. Pohrebennyk, V., Mitryasova, O., Kłos-Witkowska, A., Dzhumelia, E. (2017) The role of monitoring the territory of industrial mining and chemical complexes at the stage of liquidation. International Multidisciplinary Scientific GeoConference Surveying Geology and Mining Ecology Management, SGEM, 17(33), Vienna, Austria, 383-390.

40. Prívarová, R. (2016) Operational analysis tools in solving transport tasks. Článok uverejnený v Pernerś contact, 2, XI, July 2016.

41. Przystupa, K. (2013) Wybór punktów krytycznych w systemie HACCP. Przemyst Spożywczy, 67, 8.

42. Przystupa, K. (2015) Dobra Praktyka Transportowa. Wybrane zagadnienia. Przemyst Spożywczy, 69.

43. Przystupa, K. (2018, December) Reliability Assessment Method of Device Under Incomplete Observation of Failure. In: 18th International Conference on Mechatronics-Mechatronika, IEEE.

44. Przystupa, K. (2019) The methods analysis of hazards and product defects in food processing. Czech Journal of Food Sciences, 37(1), 44-50.

45. Przystupa, K., Koziel, J. (2018, September) Analysis of the quality of uninterruptible power supply using a UPS. In: 2018 Applications of Electromagnetics in Modern Techniques and Medicine, IEEE.

46. Selech, J., Andrzejczak, K. (2020) An aggregate criterion for selecting a distribution for times to failure of components of rail vehicles. Eksploatacja i Niezawodnosc - Maintenance and Reliability 22(1): 102-111. URL: http://dx.doi.org/10.17531/ein.2020.1.12.

47. Selech, J., Andrzejczak, K., Młyńczak, M. (2018) IT system for supporting cost-reliability analysis of fleet vehicles. Journal of KONBiN 46, 87-109. DOI 10.2478/jok-2018-0025.

48. Sengamalaselvi, J. (2017) Solving transportation problem by using Matlab. International Journal of Engineering Sciences \& Research Technology, 6(1), 374-381. DOI: 10.5281/zenodo.259588.

49. Shu, C., Kochan, O. (2013) Method of thermocouples self verification on operation place. Sensors \& Transducers, 160(12), 55.

50. Tamannaei, M., Irandoost, I. (2019) Carpooling problem: A new mathematical model, branch-andbound, and heuristic beam search algorithm. Journal of Intelligent Transportation Systems. 23(3).

51. Tawfik, C., Limbourg, S. (2018) Pricing Problems in Intermodal Freight Transport: Research Overview and Prospects. Sustainability, 10(9), 3341.

52. Trystram, D. (2011) Multi-Criteria Optimization and its Application to Multi-Processor Embedded Systems (Doctoral dissertation, PhD thesis, université de Provence).

53. Vasylkiv, N., Kochan, O., Kochan, R., Chyrka, M. (2009, September) The control system of the profile of temperature field. In: 2009 IEEE International Workshop on Intelligent Data Acquisition and Advanced Computing Systems: Technology and Applications, IEEE.

54. Vats, B., KumarSingh, A. (2016) Solving Transportation Problem using Excel Solver for an Optimal Solution. MIT International Journal of Mechanical Engineering, 6(1), 18-20.

55. Wang, J., Kochan, O., Przystupa, K., Su, J. (2019) Information-measuring System to Study the Thermocouple with Controlled Temperature Field. Measurement Science Review, 19(4), 161-169.

56. Wojciechowski, S., Wiackiewicz, M., Krolczyk, G. M. (2018) Study on metrological relations between instant tool displacements and surface roughness during precise ball end milling. Measurement, 129, 686-694.

57. Yeromenko, V., Kochan, O. (2013, September) The conditional least squares method for thermocouples error modeling. In: 2013 IEEE 7th International Conference on Intelligent Data Acquisition and Advanced Computing Systems (IDAACS), IEEE, 1, 157-162.

58. Zabolotnii, S., Mogilei, S. (2019) Features of constructing of reference plans of multimodal transport problem with constraints on load-carrying capacity. In: International School-Seminar Intelligent Solutions. Decision Making Theory. Uzhgorod, Ukraine.

59. Zabolotnii, S., Mogilei, S. (2019) Optimization of the method of constructing reference plans of multimodal transport problem. Technology audit and production reserves, 1, 2, 45, 15-20.

60. Zhang, X., Chen, M. (2018) Bi-objective routing problem with asymmetrical travel time distributions. Journal of Intelligent Transportation Systems, 22(2), 87-98. 